\title{
EL PAPEL DE LA REGIÓN DE LA ASEAN EN LA FUTURA ECONOMÍA GLOBAL*
}

\author{
Téffilo C. Daquila \\ UNIVERSIDAd Nacional de Singapur
}

$\mathrm{E}$

ste documento provee una evaluación retrospectiva del papel de la ASEAN en los últimos 30 años, un análisis de los temas actuales y algunas tendencias o perspectivas para su futuro con relación a la economía global.

La región de la ASEAN ha sido una de las más dinámicas del mundo, pues se ha transformado de una región acosada por grandes problemas económicos y polfticos en una región bendecida por la paz y la prosperidad. Registró un crecimiento promedio de alrededor del $7 \%$ durante un periodo de 30 años. A medida que la región se desarrolla y crece, tiene importantes papeles que desempeñar, no sólo para sí misma, sino también para la economía global.

- Este articulo aparecerá como capitulo del libro: The Official Briefing: ASEAN, que será publicado conjuntamente por el Centro de Investigación de Mercados Mundiales (Londres), el Consejo US-ASEAN y el Secretariado de la ASEAN.
En el frente económico, el papel de la ASEAN reside en las áreas del comercio y las inversiones. La región ha sido tanto exportadora como importadora de bienes y servicios. También ha recibido inversiones extranjeras y se ha convertido recientemente en inversionista en otras partes del mundo. Asimismo, la ASEAN ha sido productora y distribuidora de bienes y servicios no sólo en la región, sino incluso en el resto del mundo.

En tanto exportadora, el papel de la ASEAN se ha hecho cada vez más importante. Actualmente, es el tercer grupo regional más grande de exportadores después de la Unión Europea y de los Estados Unidos. En 1994, las exportaciones globales se valoraron en 4,2 billones de dolares, de las cuales la ASEAN represento el 6\%. La Unión Europea es la más grande exportadora, con una participación del $39 \%$, seguida de los Estados Unidos, con 18\%. En tanto importadora, la ASEAN ha sido una fuente importante de divisas para 
el resto del mundo. En la actualidad es el tercer importador regional más grande del mundo. Las importaciones globales alcanzaron 4,27 billones de dólares, de los cuales la ASEAN participó con $6,4 \%$. La Unión Europea y los Estados Unidos son los principales importadores, su participación en el total llega al $37 \%$ y al $22 \%$, respectivamentc.

Como exportadora, la ASEAN ha sido fuente de bienes agrícolas y materias primas para el mundo. Sin embargo, su papel como proveedora de materias primas ha disminuido $y$, en cambio, se ha convertido en exportadora principal de bienes manufacturados, no sólo en el ámbito regional, sino también mundial. La estructura de las importaciones de la ASEAN también ha cambiado, por lo cual su dependencia de artículos manufacturados ha continuado creciendo, particularmente sus importaciones de maquinaria y equipo de transporte. El giro en la política de industrialización de la ASEAN, desde la sustitución de importaciones en los cincuenta y sesenta hacia una política orientada a la exportación desde los setenta, ha contribuido a la estructura cambiante del comercio de esta región. Durante el periodo de sustitución de importaciones se permitía la importación de bienes intermedios y de capital, pero se restringía la importación de productos de consumo. Las políticas orientadas a las exportaciones se centraban en la promoción de bienes manufacturados, siguiendo una política de diversificación, debido a la cafda de los precios de las materias primas.

En tanto receptora de inversión extranjera directa, la región ofrece ventajas de ubicación, incluyendo abundancia de materia prima, bajo costo de la mano de obra, incentivos generosos a la inversión, fuerza de trabajo calificada y trabajadora, infraestructura mejorada y ambiente políticamente estable. La ASEAN es el tercer receptor mayor de inversión extranjera directa. En 1995, la inversión extranjera directa total global fue de $316 \mathrm{mil}$ millones de dólares, de los cuales la ASEAN participo con el 7\%. La Unión Europea concentra la participación más grande, $38 \%$, scguida de los Estados Unidos, con $19 \%$. Las inversiones de cartera también han estado ascendiendo. Se informó que la inversión global de cartera fue $539 \mathrm{mil}$ millones de dólares, de los cuales $2 \%$ fueron a la ASEAN.

La mayor parte de las inversiones extranjeras directas han sido en el sector manufacturero. Sin embargo, los tipos de inversión extranjera directa han cambiado en este periodo de 30 años. El primer tipo tenía como fin aprovechar la abundan. cia de minerales y de combustibles de la región, incluyendo petróleo y gas. Los británicos, los estadounidenses y los japoneses tienen grandes inversiones del primer tipo en la región. El segundo tipo ha permitido a los inversionistas extranjeros acceder al mercado regional nacional. Durante la etapa de sustitución de importaciones, las industrias manufactureras usaban capital, tecnología y administración traídos por los inversionistas extranjeros y los bienes se producían usando las maquinarias y el equipo de transporte importados de Occidente. Los productos, principalmente bienes de consumo manufacturados, se destinaron a la población nacional de la ASEAN. El tercer tipo de inversión se orienta al comercio. Desde los setenta, los inversionistas extranjeros se centraron en el sector manufacturero, cuyos productos se distribuyen no sólo en la región, sino también en el mercado de ultramar. 
La ASEAN no es sólo receptora de inversión extranjera, también ha sido inversionista. En 1995, las inversiones extranjeras directas ascendían a $297 \mathrm{mil} \mathrm{mi-}$ llones de dólares, de los cuales la ASEAN participaba con $2 \%$ (5.794 millones). Debido a condiciones laborales difíciles, Singapur y Malaysia han invertido en los nuevos miembros de la ASEAN, en otros países asiáticos (China e India) y en otras partes del mundo. La región también se ha convertido crecientemente en una fuente importante de inversiones de cartera, a medida que crecen los ahorros regionales por el incremento en el ingreso per cápita. Las inversiones de cartera globales estaban en 412 mil millones de dólares, de los cuales la región de la ASEAN participaba con $2 \%$.

En el frente político, la ASEAN tiene un papel crucial que desempeñar. Como está ubicada estratégicamente, ha proporcionado seguridad y estabilidad no sólo a la región, sino al mundo, en general, y a la región del Asia Pacífico, en particular. Entre los factores que contribuyen a esto se puede mencionar: ingreso per cápita más alto de la población, gobierno y política estables, evitamiento o solución de las disputas territoriales (incluyendo la de las Islas Spratly), condiciones de paz y orden mejoradas y la presencia militar de los Estados Unidos en la región. La formación del Foro Regional de la ASEAN ha sido también un factor importante. La ASEAN ha actuado consistentemente por consenso, lo que se conoce como "la manera de la ASEAN", y ha fortalecido la solidaridad y la cooperación en la región. La estabilidad y la paz en la región acrecientan las relaciones económicas de la ASEAN con otros países, particularmente en el campo del comercio y las inversiones.
Hay acontecimientos que suceden en otras partes del mundo, así como en la región, que ciertamente causan impacto en el papel que cumple la ASEAN en los campos político y económico, pero debido a la creciente integración de la economía mundial, estos acontecimientos también afectan al resto del mundo. Más aún, la región de la ASEAN es pequeña, de modo que lo que sucede en regiones más grandes, como Norteamérica y Europa, se transmite a la ASEAN.

En primer lugar está la formación de acuerdos comerciales regionales en el mundo, incluyendo el Acuerdo de Libre Comercio Norteamericano (NAFTA), la Unión Europea, el Área de Libre Comercio de la ASEAN (AFTA), el Mercosur y las Relaciones Económicas más Cercanas entre Australia y Nueva Zelandia (CER), para nombrar sólo unos pocos. A pesar de que estos acuerdos regionales tienen un sentido proteccionista, las tendencias actuales de la globalización indican que el mundo se dirige hacia el comercio e inversión $\sin$ fronteras en búsqueda del regionalismo abierto. Los acuerdos comerciales regionales deberian romper las barreras no sólo entre sus respectivos miembros, sino también entre los diferentes grupos regionales.

En segundo lugar están las relaciones económicas entre la ASEAN y Europa. A través del primer ministro de Singapur, Goh Chok Tong, la ASEAN inició la Reunión Cumbre Asia-Europa (ASEM), que se realizó en Bangkok en marzo de 1996. Como reunió a líderes de la ASEAN, la Unión Europea-15, China, Japón y Corea, esta cumbre es un paso importante hacia una relación más amplia y significativa. La ASEAN debería ser la piedra angular de estas relaciones entre Asia y Europa 
e impulsar la institucionalización de la reunión cumbre para obtener un compromiso político y una dedicación mayor de todos los lideres involucrados.

En tercer lugar está lo realizado entre la ASEAN y algunos países del Asia Pacífico a través de un foro comercial conocido como la Cooperación Economica del Asia Pacifico (APEC). El grupo se reunió en Manila en 1996 y produjo un documento significativo conocido como el Plan de Acción de Manila (MAPA), con el que se ha establecido exitosamente el fundamento para lograr las metas trazadas en Bogor (Indonesia), que son liberar el comercio y la inversión en la región en el 2010 y el 2020. Los líderes de la APEC acordaron respaldar un acuerdo global que eliminará la mayor parte de aranceles a los productos de tecnología de la información para el año 2000, incluyendo computadoras, semiconductores, software y equipos de telecomunicaciones. Como la APEC concentraba el $46 \%$ de las exportaciones globales y el $47 \%$ de las importaciones globales, debería tomar el liderazgo de la Organización Mundial del Comercio, OMC. Tanto la ASEAN comoel NAFTA pueden dirigir el camino. APEC debería complementar y no competir con la OMC.

En cuarto lugar están las relaciones económicas entre la ASEAN y la Organización Mundial de Comercio. En la ASEAN, Singapur fue el anfitrión de las dos primeras reuniones de la OMC en diciembre de 1996, que congregaron a ministros y representantes de los países miembros y produjeron un documento muy importante conocido como el "Acuerdo sobre Tecnología de la Información", que liberalizará la industria de la tecnología de la información a escala global. El pa- quete global de tecnología de la información vale ahora anualmente $500 \mathrm{mil}$ millones de dólares, y los miembros de la APEC representan $80 \%$ de ese total.

La OMC reemplaza el Acuerdo General sobre Aranceles y Comercio(GATT) como resultado de las negociaciones comerciales de la Ronda de Uruguay, que duraron siete años. Actualmente la OMC cuenta con 119 miembros. Otros países están buscando la membresía, incluyendo a China, Taiwan, Rusia y Vietnam. Laos, Myanmar y Camboya también solicitarán ser miembros de la OMC. Sin embargo, necesitan introducir reformas importantes para cumplir con los requisitos establecidos por la OMC, y este proceso toma tiempo.

La OMC apunta a implementar los resultados de la Ronda de Uruguay, esto es: (a) que los países miembros implementen compromisos de reducciones de aranceles en productos industriales, (b) que las cuotas en la importación de productos agrícolas, textiles y de confección se reemplacen con aranceles menos restrictivos, (c) que se desmantele el Acuerdo Multifibras, (d) que el comercio en textiles y confecciones se integre a las reglas normales del GATT, y (e) que se fortalezca el mecanismo de solución de disputas, incluyendo el Cuerpo de Apelación recientemente creado.

La OMC también ha tomado la iniciativa para liberalizar el comercio de servicios. En 1995, las exportaciones de servicios se valoraron en 1,23 billones de dólares. Con una participación de $17 \%$, los Estados Unidos han ofrecido liberalizar su sector financiero dando accesc irrestricto al mercado a las compañías extranjeras, no sólo a las operaciones exis- 
tentes, sino a todas las instituciones extranjeras, y tanto para nuevos servicios financieros como para expandir los existentes. La Unión Europea es el exportador de servicios más grande, con una participación del $46 \%$. Sometió su ofrecimiento de liberalizar su sector financiero en julio de 1997. Se está alentando a otros países, incluidos los de la ASEAN, a que abran sus mercados financieros y sometan su ofrecimiento a la reunión de la OMC de diciembre de 1997.

Por su parte, la ASEAN ha tomado medidas para apoyar ambas iniciativas regionales, el AFTA y la APEC, y las iniciativas multilaterales de la OMC. Primero, la ASEAN ha tomado medidas para liberalizar la comercialización de bienes. Desde 1993, se implementó el Acuerdo sobre Aranceles Preferenciales Comunes para promover el comercio regional. Las tasas arancelarias se han cortado $y$ las barreras no arancelarias se han rebajado. Las últimas cifras indican que el comercio al interior de la ASEAN se ha incrementado en aproximadamente $25 \%$ del comercio total de la ASEAN en 1996. En el año 2003, la región alcanzará el Área de Libre Comercio (AFTA), cuyos beneficios incluirán el aumento de la producción y el consumo regionales, economías de escala, y presencia de más corporaciones transnacionales en la región.

Segundo, la ASEAN también ha tomado medidas para liberalizar el comercio de servicios. El sector servicios ha crecido significativamente en la ASEAN, lo que se refleja en su participación en los resultados totales. En la medida en que la ASEAN crece y se eleva el ingreso per cápita, sus poblaciones demandan más bienes y servicios. Se ha creado más servicios $\mathrm{e}$ instituciones para satisfacer la creciente demanda, lo que se expresa en la creciente importancia del sector servicios, principalmente de los servicios financieros y de negocios, así como de transportes y comunicaciones. La ASEAN representó el 5,4\% (66,7 mil millones de d6́lares) de las exportaciones globales de servicios. Singapur es el exportador de servicios más grande (29,4 mil millones de dólares), seguido de Tailandia (14,8 mil millones de dólares), Filipinas $(9,3 \mathrm{mil}$ millones de dólares), Malaysia (6,5 mil millones de dólares) e Indonesia (5,7 mil millones de dólares). En cuanto a las importaciones, la ASEAN participó con el $5,2 \%$ de la importaciones globales de servicios, que llegaron a 1,26 billones de dólares en 1995 y se distribuyeron de la siguiente manera (en miles de millones de dólares): Tailandia $(18,8)$, Singapur $(16,6)$, Indonesia $(13,4)$, Malaysia (9) y Filipinas (7).

Tercero, la ASEAN ha tomado medidas de liberalización de la inversión. Las reglas de inversión se han hecho menos estrictas y se ha otorgado incentivos más generosos. La ASEAN también ha adoptado algunos esquemas con los que se incrementarán las inversiones en la región. Primero, está el esquema del Área de Inversión de la ASEAN (AIA), que alentará una mayor participación del sector privado y dará la bienvenida a los inversionistas extranjeros. Segundo, está el esquema de cooperación subregional Triángulo del Crecimiento, desarrollado en el contexto de las ventajas comparativas y basado en la dotación de factores. Éstos incluyen el triánguloSingapur-Johoir (Malaysia)-Riau (Indonesia) y el Área de Crecimiento del Sudeste de Asia (EAGA) conformada por Brunei. Indonesia, Malaysia y las Filipinas. El tercer esquema se conoce como la Cooperación Industrial de la ASEAN 
(AICO), que permite los joint ventures entre ciudadanos de la ASEAN e inversionistas extranjeros y a cuyos productos y servicios se les dará un arancel más bajo.

Cuarto, la ASEAN también ha aprendido de las perturbaciones en la región y ha respondido a éstas. Recientemente, la región sufrió una crisis financiera causada por la debilitación de sus monedas nacionales frente a las monedas extranjeras, en particular el dólar estadounidense. El problema financiero se originó en Tailandia debido al exceso de préstamos de los bancos y compañías financieras. El baht de Tailandia, el peso filipino y el ringgit de Malaysia sufrieron ataques especulativos que ocasionaron la devaluación de estas monedas. La moneda de Singapur también resultó ligeramente afectada, pero este país vino inmediatamente al rescate del baht tailandés. El FMI también otorgó préstamos por 15 mil millones de d6lares para ayudar a la recuperación de la economia tailandesa.

Para evitar estas crisis, los gobiernos de la ASEAN deberían adoptar una política fiscal prudente que aseguraria un déficit presupuestal que la economía puede absorber. A su vez, esto permitirá que sus gobiernos controlen la inflación y administren apropiadamente sus empréstitos nacionales y extranjeros. La ASEAN debería evitar que se sobrevalúen las tasas de interés, lo que permitiría que las tasas de cambio busquen sus niveles realistas. Más aún, la ASEAN debería fortalecer su cooperación financiera, incluyendo la prestación de asistencia a los países miembros en tiempos de crisis financiera, $e$ institucionalizar la reunión de ministros de finanzas de la ASEAN.

Quinto, la ASEAN también ha respon- dido a problemas políticos y de seguridad que acarrean consecuencias para la región y el resto del mundo. El primero fue la crisis de Camboya. El Acuerdo de Paz de París de 1991 puso fin a la guerra de Camboya y preparó el camino para las elecciones de 1993, en las que el príncipe Ranaridoh y su partido realista resultaron ganadores. El príncipe acordó establecer una coalición con el Sr. Hun Sen, quien lo destronó luego de una lucha violenta el 6de julio. Losfuncionarios de la ASEAN se han esforzado por resolver el conflicto pacíficamente a través de un compromiso constructivo y no a través de medios violentos. Si la crisis continúa, afectará a la ASEAN, ya que su estabilidad política, su desempeño económico y su credibilidad internacional están en juego.

La ASEAN también se ha expandido hacia ASEAN-9 con la reciente admisión de Laos y Myanmar. Se espera que Camboya se una al grupo hacia el final de este año, lo que haría realidad el sueño de la región de convertirse en ASEAN10. La expansión de la ASEAN significa una población de alrededor de $500 \mathrm{mi}$ llones de personas y un ingreso regional de alrededor de 1 billón de dólares. El enorme mercado regional y el creciente ingreso per cápita de la población de la ASEAN ofrecen tremendas oportunidades de inversión y comercio al resto del mundo. Para lograr el sueño de ser ASEAN-10, la organización está atareada por el compromiso constructivo con Myanmar y Camboya. La ASEAN también es responsable de proveer ayuda técnica y financiera a los miembros más pobres del grupo para aminorar las diferencias entre los ingresos nacionales y evitar así que en la región se formen dos grupos. Sin embargo, no se debería dejar sola a la ASEAN en lo que respecta a su segunda 
tarea. Las economías desarrolladas y las organizaciones internacionales también deberian prestar su ayuda, ya que el desarrollo de toda la región es beneficioso no sólo para la ASEAN, sino también para éstas.

Para concluir, las recientes tendencias, incluyendo la globalización, la liberalización y la tecnología de cambios rápidos indican que el mundo estarámuy integrado y que las naciones y regiones serán altamente interdependientes. La economía global se encamina hacia un ambiente que promueve la libertad del comercio y de las inversiones. La producción internacional de bienes y servicios se realizará a mayor escala. Secomerciarácon los bienes y servicios libremente a escala global. Los flujos de capital, en forma de inversión extranjera directa y de inversiones de cartera, se moverán libremente por cl mundo en busca de tasas de retorno más aitas. Habrá una competencia más fuerte para el comercio y las inversiones ya que las regiones y naciones competirán entre sí. También habrá oportunidades para la complementación. Las naciones compi- ten y cooperan al mismo tiempo para conseguir una situación gana-gana. Por lo tanto, lo que se necesita es una estrategia de cooperación competitiva.

La ASEAN, por su parte, continuará creciendo dinámicamente en la futura economía global y siendo un actor muy importante en ésta. Desempeñará sus diferentes papeles con mucha fuerza y vigor, tanto los económicos -de exportador, importador, receptor de inversión extranjera, inversionista-como los políticos -de proveedor de seguridad y estabilidad para la región y el mundo en su conjunto-.

Para que la ASEAN cumpla su papel en el orden económico y en el orden politico, deberá mantener un ambiente macroeconómico estable adoptando una política fiscal prudente, profundizar y ampliar sus medidas de liberalización del comercio y la inversión, apoyar el regionalismo abierto, alentar el involucramiento del sector privado y mantener la estabilidad política y la seguridad de la región. 